\title{
Studi Plasma Immersion Ion Implantation (PIII) dengan menggunakan Target Tak Planar
}

\author{
Yoyok Cahyono* \\ Jurusan Fisika, FMIPA-Institut Teknologi Sepuluh Nopember (ITS) \\ Kampus ITS Sukolilo, Surabaya 60111
}

Intisari

Telah dilakukan studi proses PIII dengan menggunakan model sheath dinamis tanpa tumbukan plasma multispesies bermuatan tunggal dan ganda dengan bentuk target silinder dan bola. Bentuk Pulsa tegangan yang digunakan adalah tegangan realistis. Dalam model ini ditentukan ekspansi sheath dinamis dan rapat arus ion implan total dengan menggunakan massa efektif yang merupakan fungsi dari komposisi, keadaan muatan dan massa ion dari masing-masing spesies yang berbeda.

KATA KUNCI: Sheath dinamis, plasma multispesies, muatan ganda, tegangan realistis, target tak planar

\section{PENDAHULUAN}

Implantasi ion sudah sering digunakan dalam teknik fabrikasi pembuatan semikonduktor dan proses pelapisan dalam bidang metalurgi dan optik. Plasma Immersion Ion Implantation (PIII) adalah salah satu teknik implantasi, dimana target tercelup dalam plasma seperti tampak pada Gambar 1 [1]. Model sheath dinamis mempunyai peran yang sangat penting dalam proses PIII. Model ini dapat digunakan untuk memprediksi parameter proses dan hasil implantasi dengan memasukkan doses implan dan profil impuritas. Konfigurasi sistem plasma yang optimal dapat ditentukan dari karakteristik ekspansi sheath.

Conrad, Lieberman, Scheuer dan Shamim [2-4], membuat model sheath dinamis tanpa tumbukan untuk plasma spesies tunggal. Saat tegangan negatif diberikan pada target yang tercelup dalam plasma akan terbentuk sheath. Sheath akan berubah tehadap waktu dan akan memenuhi hukum ChildLangmuir. Model sheath dinamis tanpa tumbukan ini telah dibuktikan dengan pengukuran oleh Shamim [4], dan dengan simulasi numerik oleh S.J. Hanh dan Lee.

Model sheath plasma spesies tunggal telah banyak digunakan walaupun dalam kenyataannya plasma yang digunakan dalam proses PIII adalah plasma multispesies. Thomas menggunakan model fluida untuk menghitung sheath dinamis dari plasma dua spesies $\left(\mathrm{N}^{+}\right.$dan $\left.\mathrm{N}_{2}^{+}\right)$untuk implantasi ion. Qin, dkk [5] dan Cahyono [6] mengembangkan model sheath dinamis tanpa tumbukan plasma multispesies bermuatan tunggal dengan menggunakan contoh plasma Ar-He dan BF3 yang masing-masing spesiesnya dianggap bermuatan tunggal untuk studi proses PIII.

Model sheath dinamis tanpa tumbukan plasma multispesies bermuatan ganda dikembangkan oleh Qin, dkk [7], dimana keadaan muatan dari ion-ion spesiesnya diperhatikan. Bentuk Pulsa tegangan yang digunakan adalah tegangan ko-

*E-MAIL: yoyok@physics.its.ac.id

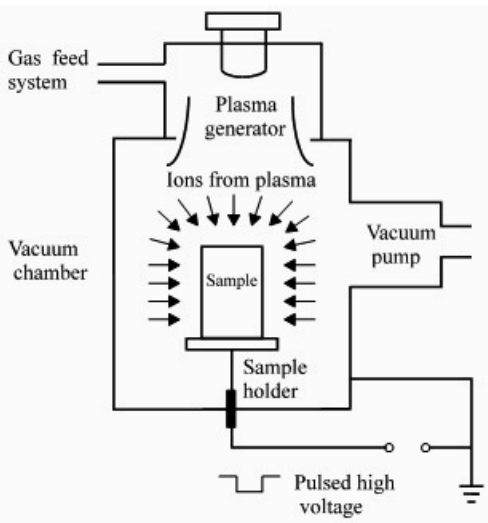

(a)

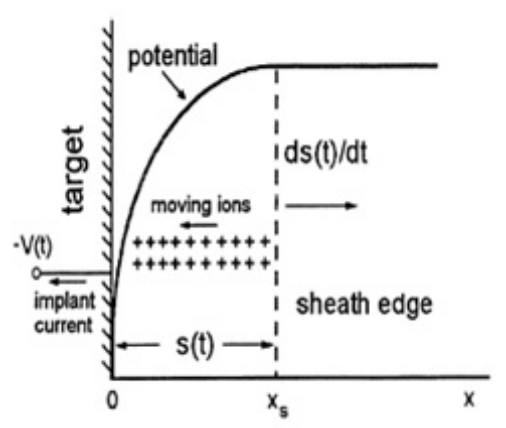

(b)

Gambar 1: (a). Skema teknik Plasma Immersion Ion Implantation (PIII)(b). Skema ekspansi sheath

tak. Menurut Stewart dkk [8] , dalam eksperimen PIII waktu naik dan waktu turun pulsa tegangan merupakan bagian signifikan dari keseluruhan lebar pulsa, sehingga agar model yang dikembangkan ini lebih representatif dan lebih realistis, maka keadaan pulsa tegangan realistik ini seharusnya dimasukkan kedalam perhitungan. Model yang dikembangkan oleh Qin, dkk ini [7] , dikembangkan lagi oleh Cahyono [8] dengan menggunakan bentuk pulsa tegangan ini. Dalam studi 
ini model yang telah dikembangkan pada waktu yang lalu [9] , diperluas lagi dengan menggunakan bentuk target silinder dan bola. Karena target yang dipakai dalam eksperimen atau aplikasi proses PIII juga menggunakan bentuk-bentuk ini[5].

\section{MODEL SHEATH DINAMIS PLASMA MULTISPESIES DENGAN TARGET TAK PLANAR}

Dalam studi ini, bentuk target silinder dan bola yang ditinjau adalah satu dimensi dengan semua fungsi diambil kedalam variabel $r$, yang menunjukkan arah radial koordinat. Untuk mempermudah perumusan dianggap bahwa plasma terdiri dari 2 spesies ion yang mempunyai rapat ion masing-masing $\mathrm{n}_{1}$ untuk spesies bermuatan tunggal $\mathrm{A}^{+}$dan $\mathrm{n}_{2}$ untuk spesies bermuatan ganda $\mathrm{A}^{++}$. Distribusi tegangan ditentukan oleh persamaan Poisson

$$
\begin{aligned}
\frac{\partial}{r^{p} \partial r}\left(r^{p} \frac{d V}{d r}\right) & =\frac{-\rho}{\epsilon_{\circ}}=\frac{-q}{\epsilon_{\circ}}\left(n_{e}-n_{i}\right) \\
& =\frac{-q}{\epsilon_{\circ}}\left[n_{e}-\left(n_{1}+2 n_{2}\right)\right]
\end{aligned}
$$

dengan $\mathrm{p}=1$ untuk silinder dan $\mathrm{p}=2$ untuk bola, $n_{i}=n_{1}+2 n_{2}$ adalah rapat ion total plasma dan $\mathrm{n}-e$ adalah rapat elektron.

Rapat arus ion yang masuk target dapat ditulis

$$
J_{i}=q n_{i}(r) \bar{v}_{i}(r)
$$

dari hukum kekekalan energi, didapatkan

$$
\frac{1}{2} m_{i} \bar{v}_{i}^{2}(r)=q V(r)
$$

sehingga,

$$
\bar{v}_{i}(r)=\sqrt{\frac{2 q V(r)}{m_{i}}}
$$

dengan demikian, maka rapat arus ion jenis-1 adalah

$$
\begin{aligned}
J_{1} & =q n_{1}(r) \bar{v}_{1}(r) \\
& =q n_{1}(r) \sqrt{\frac{2 q V(r)}{m_{A}}}
\end{aligned}
$$

akhirnya didapatkan rapat ion jenis-1

$$
n_{1}=\frac{J_{1}}{q \sqrt{\frac{2 q V(r)}{m_{A}}}}
$$

dengan cara yang sama, didapatkan rapat ion jenis-2

$$
n_{2}=\frac{J_{2}}{2 q \sqrt{\frac{4 q V(r)}{m_{A}}}}
$$

Ketika diberikan tegangan tinggi negatip, rapat elektron didalam sheath sama dengan nol $\left(\mathrm{n}_{e}=0\right)$, karena elektron dipantulkan kembali oleh lapisan sheath. Sehingga dari Pers.
(6) dan (7), persamaan Poisson pada Pers. (1) kemudian menjadi

$$
\frac{1}{r^{p}} \frac{d}{d r}\left(r^{p} \frac{d V}{d r}\right)=\frac{1}{\epsilon_{\circ}}\left(J_{1} \sqrt{\frac{m_{A}}{2 q}}+J_{2} \sqrt{\frac{m_{A}}{4 q}}\right) V^{-1 / 2}
$$

Persamaan ini untuk bentuk target silinder dan bola, berturutturut dapat ditulis menjadi

$$
\begin{aligned}
& \frac{d^{2} V}{d r^{2}}+\frac{1}{r} \frac{d V}{d r}=\frac{1}{\epsilon_{\circ}}\left(J_{1} \sqrt{\frac{m_{A}}{2 q}}+J_{2} \sqrt{\frac{m_{A}}{4 q}}\right) V^{-1 / 2} \\
& \frac{d^{2} V}{d r^{2}}+\frac{2}{r} \frac{d V}{d r}=\frac{1}{\epsilon_{\circ}}\left(J_{1} \sqrt{\frac{m_{A}}{2 q}}+J_{2} \sqrt{\frac{m_{A}}{4 q}}\right) V^{-1 / 2}
\end{aligned}
$$

dengan mengalikan Pers. (9) dengan $\sqrt{V}$, didapatkan

$$
\begin{aligned}
& \frac{d^{2} V^{3 / 2}}{d r^{2}}+\frac{1}{r} \frac{d V^{3 / 2}}{d r}=\frac{3}{2 \epsilon_{\circ}}\left(J_{1} \sqrt{\frac{m_{A}}{2 q}}+J_{2} \sqrt{\frac{m_{A}}{4 q}}\right) \\
& \frac{d^{2} V^{3 / 2}}{d r^{2}}+\frac{2}{r} \frac{d V^{3 / 2}}{d r}=\frac{3}{2 \epsilon_{\circ}}\left(J_{1} \sqrt{\frac{m_{A}}{2 q}}+J_{2} \sqrt{\frac{m_{A}}{4 q}}\right)
\end{aligned}
$$

dengan menganggap $z=\frac{d V^{3 / 2}}{d r}$, maka Pers. (10) dapat ditulis

$$
\begin{aligned}
& \frac{d z}{d r}+\frac{1}{r} z=\frac{3}{2 \epsilon_{\circ}}\left(J_{1} \sqrt{\frac{m_{A}}{2 q}}+J_{2} \sqrt{\frac{m_{A}}{4 q}}\right) \\
& \frac{d z}{d r}+\frac{2}{r} z=\frac{3}{2 \epsilon_{\circ}}\left(J_{1} \sqrt{\frac{m_{A}}{2 q}}+J_{2} \sqrt{\frac{m_{A}}{4 q}}\right)
\end{aligned}
$$

yang merupakan persamaan Bernoulli, sehingga solusinya dapat ditulis

$$
\begin{aligned}
& z=\frac{d V^{3 / 2}}{d r}=\frac{3}{4 \epsilon_{\circ}}\left(J_{1} \sqrt{\frac{m_{A}}{2 q}}+J_{2} \sqrt{\frac{m_{A}}{4 q}}\right) r+\frac{c_{1}}{r} \\
& z=\frac{d V^{3 / 2}}{d r}=\frac{1}{2 \epsilon_{\circ}}\left(J_{1} \sqrt{\frac{m_{A}}{2 q}}+J_{2} \sqrt{\frac{m_{A}}{4 q}}\right) r+\frac{c_{2}}{r^{2}}
\end{aligned}
$$

Dengan mengambil konstanta $c_{1}=c_{2}=0$, maka jika diintegralkan akan memberikan

$$
\begin{aligned}
\int_{0}^{V^{3 / 2}} d V^{3 / 2} & =\int_{0}^{s} \frac{3}{4 \epsilon_{\circ}}\left(J_{1} \sqrt{\frac{m_{A}}{2 q}}+J_{2} \sqrt{\frac{m_{A}}{4 q}}\right) r d r \\
\int_{0}^{V^{3 / 2}} d V^{3 / 2} & =\int_{0}^{s} \frac{1}{2 \epsilon_{\circ}}\left(J_{1} \sqrt{\frac{m_{A}}{2 q}}+J_{2} \sqrt{\frac{m_{A}}{4 q}}\right) r d r
\end{aligned}
$$

dan menghasilkan

$$
\begin{aligned}
\frac{8}{3} \epsilon_{\circ} \frac{V^{3 / 2}}{s^{2}} & =J_{1} \sqrt{\frac{m_{A}}{2 q}}+J_{2} \sqrt{\frac{m_{A}}{4 q}} \\
4 \epsilon_{\circ} \frac{V^{3 / 2}}{s^{2}} & =J_{1} \sqrt{\frac{m_{A}}{2 q}}+J_{2} \sqrt{\frac{m_{A}}{4 q}}
\end{aligned}
$$


Dari hasil penelitian yang lalu [10], bahwa didalam proses PIII dapat dianggap ekspansi sheath didominasi oleh arus ion mantap, yaitu arus ion tidak bergantung waktu atau konstan. Dengan demikian rapat arus masing-masing spesies dapat ditulis

$$
\begin{aligned}
& \frac{J_{1}}{J}=\frac{k_{1} q n_{i} \overline{v^{\prime}}}{q n_{i} \overline{v^{\prime}}} \quad \text { atau } \quad J_{1}=\frac{n_{1}}{n_{1}+2 n_{2}} J \\
& \frac{J_{2}}{J}=\frac{k_{2} q n_{i} \overline{v^{\prime}}}{q n_{i} \overline{v^{\prime}}} \quad \text { atau } \quad J_{2}=\frac{2 n_{2}}{n_{1}+2 n_{2}} J
\end{aligned}
$$

dengan memasukkan Pers. (14) kedalam Pers. (15) akan diperoleh

$$
\begin{aligned}
& J=\frac{8}{3} \epsilon_{\circ} \sqrt{\frac{2 q}{M}} \frac{V^{3 / 2}}{s^{2}} \\
& J=4 \epsilon_{\circ} \sqrt{\frac{2 q}{M}} \frac{V^{3 / 2}}{s^{2}}
\end{aligned}
$$

Pers. (16) ini adalah persamaan arus Child-Langmuir,

$$
\begin{aligned}
\sqrt{M} & =\frac{n_{1}}{n_{1}+2 n_{2}} \sqrt{m_{A}}+\frac{n_{2}}{n_{1}+2 n_{2}} \sqrt{2 m_{A}} \\
\text { atau } & \sqrt{M}=k_{1} \sqrt{m_{A}}+k_{2} \sqrt{2 m_{A}}
\end{aligned}
$$

dengan, $M$ adalah massa efektip untuk plasma yang terdiri dari 2 spesies ion dengan keadaan muatan berbeda saat arus ion dalam keadaan mantap.

Untuk hal yang lebih umum, yaitu untuk plasma yang terdiri dari banyak spesies ion, dengan mengambil analogi diatas, massa efektip saat arus ion dalam keadaan mantap dapat ditulis

$$
\sqrt{M}=\sum_{i=1}^{n} k_{i} \sqrt{c_{i} m_{i}}
$$

dengan, i menunjukkan indek ion, $c_{i}$ menunjukkan keadaan muatan, mi menunjukkan massa ion spesies ke-i, dan $k_{i}$ adalah perbandingan rapat ion jenis-i dengan rapat ion total yang secara umum ditulis

$$
k_{i}=\frac{n_{i}}{\sum_{j}^{\ell} c_{j} n_{j}}
$$

dengan, $\mathrm{j}$ indek ion, $n_{i}$ rapat ion ke-i. Rapat arus ion dapat juga dinyatakan dengan

$$
J=q n_{i} \frac{d s}{d t}
$$

dengan s merupakan posisi tepi sheath relatip terhadap target. Dengan cara yang sama seperti pada penelitian yang lalu [10], didapatkan persamaan kecepatan ekspansi sheath berturut-turut untuk bentuk silinder dan bola

$$
\begin{aligned}
& \frac{d s}{d t}=\frac{4}{3} \frac{s_{\circ}^{2} u_{\circ}}{s^{2}(t)} \widetilde{V}^{3 / 2}(t) \\
& \frac{d s}{d t}=2 \frac{s_{\circ}^{2} u_{\circ}}{s^{2}(t)} \widetilde{V}^{3 / 2}(t)
\end{aligned}
$$

dengan,

$$
\begin{aligned}
s_{\circ} & =\sqrt{\frac{2 \epsilon_{\circ} V_{\circ}}{n_{i} q}}: \text { posisi sheath mula-mula } \\
\mu_{\circ} & =\sqrt{\frac{2 q V_{\circ}}{M}}: \text { kecepatan ion karakteristik } \\
\widetilde{V}(t) & =\frac{V(t)}{V_{\circ}}: \text { posisi sheath mula-mula }
\end{aligned}
$$

Gelombang tegangan realistis yang digunakan mempunyai bentuk

$$
\begin{aligned}
& \widetilde{V}(t)=t / t_{n}: \text { untuk } 0<t<t_{n} \\
& \widetilde{V}(t)=1: \text { untuk } t_{n}<t<\left(t_{n}+t_{d}\right) \\
& \widetilde{V}(t)=\left(t_{r}-t\right) / t_{t}: \text { untuk }\left(t_{n}+t_{d}\right)<t<t_{r}
\end{aligned}
$$

dengan, $t_{r}=t_{n}+t_{d}+t_{t}$ dengan pulsa dibedakan kedalam 3 waktu yang berbeda, yaitu waktu naik $t_{n}$, waktu datar $t_{d}$, dan waktu turun $t_{t}$.

Dengan mengintegralkan Pers. (21), dan mengambil $\mathrm{s}(0)=$ 0, $\widetilde{V}(t)=t / t_{n}$, dari Pers. (22), maka diperoleh

$$
\begin{gathered}
s(t)=\left(\frac{8}{3} \omega_{p i}\right)^{1 / 3} s_{\circ} \frac{t^{5 / 6}}{t_{n}^{1 / 2}} \\
s(t)=\left(\frac{12}{5} \omega_{p i}\right)^{1 / 3} s_{\circ} \frac{t^{5 / 6}}{t_{n}^{1 / 2}}
\end{gathered}
$$

Persamaan ini merupakan gerak sheath selama pulsa naik, $0<$ $t<t_{n}$, untuk silinder dan bola. Pada waktu pulsa datar, $t_{n}<$ $t<\left(t_{n}+t_{d}\right)$, gerak sheath diperoleh dengan mengintegralkan Pers. (21) dari $t_{n}$ ke $t$ dengan $\widetilde{V}(t)=1$,

$$
\begin{aligned}
s^{3}(t) & =s^{3}\left(t_{n}\right)+4 s_{\circ}^{3} \omega_{p i}\left(t-t_{n}\right) \\
\cdot & \\
s^{3}(t) & =s^{3}\left(t_{n}\right)+6 s_{\circ}^{3} \omega_{p i}\left(t-t_{n}\right)
\end{aligned}
$$

Dengan memasukkan $s\left(t_{n}\right)$ dari Pers. (23), Pers. (24) dapat ditulis menjadi

$$
\begin{aligned}
& s(t)=s_{\circ}\left[4 \omega_{p i}\left(t-\frac{3}{5} t_{n}\right)\right]^{1 / 3} \\
& s(t)=s_{\circ}\left[6 \omega_{p i}\left(t-\frac{3}{5} t_{n}\right)\right]^{1 / 3}
\end{aligned}
$$

Akhirnya selama pulsa turun, $\left(t_{n}+t_{d}\right)<t<t_{r}$, dengan mengintegralkan Pers. (21) dari $t_{n}+t_{d}$ ke $\mathrm{t}$, dengan $\widetilde{V}(t)=$ $\left(t_{r}-t_{)}\right) / t_{t}$, maka aka diperoleh gerak sheath

$$
\begin{aligned}
& s(t)=s_{\circ}\left[6 \omega_{p i}\left\{\frac{2}{5}\left(t_{n}+t_{d}\right)\right\}-\frac{24}{15} \omega_{p i}\left\{\frac{\left(t_{r}-t\right)^{5 / 2}}{t_{t}^{3 / 2}}-t_{t}\right\}\right]^{1 / 3} \\
& s(t)=s_{\circ}\left[6 \omega_{p i}\left\{\frac{2}{5}\left(t_{n}+t_{d}\right)\right\}-\frac{12}{5} \omega_{p i}\left\{\frac{\left(t_{r}-t\right)^{5 / 2}}{t_{t}^{3 / 2}}-t_{t}\right\}\right]^{1 / 3}
\end{aligned}
$$




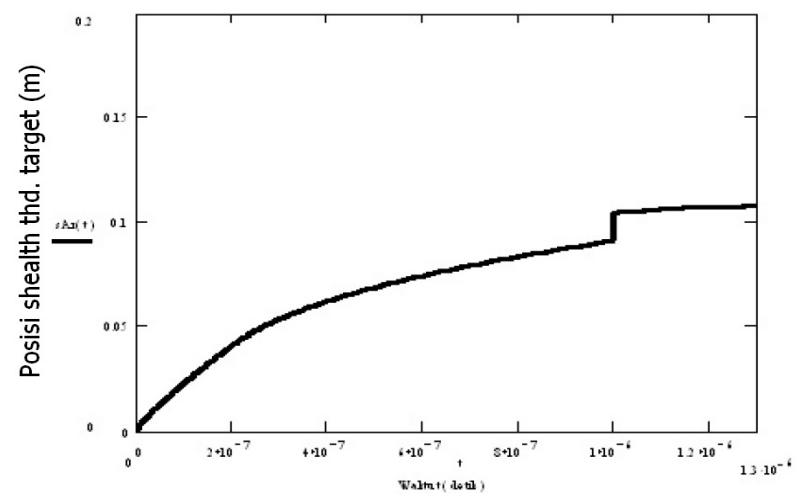

Gambar 2: Posisi sheath thd target bentuk silinder untuk plasma Argon, dengan tegangan $\mathrm{V}=-30 \mathrm{kVolt}$ dan $\mathrm{n}_{I}=6,8 \cdot 10^{15} \mathrm{~m}^{-3}$.

dengan, $s\left(t_{n}+t_{d}\right)$ diperoleh dari Pers. (25). Pers. (23) (26) memberikan gambaran posisi sisi sheath yang lengkap selama durasi pulsa tegangan yang digunakan berturut-turut untuk bentuk target silinder dan bola. Berikut akan diberikan contoh perhitungan dan analisis dengan menggunakan plasma Argon (Ar) dan plasma Argon-Helium (Ar/He).

\section{HASIL DAN PEMBAHASAN}

Plasma Argon terdiri dari ion $\mathrm{Ar}^{+}$dan $\mathrm{Ar}^{++}$, sedangkan plasma multispesies Ar-He, terdiri dari ion-ion $\mathrm{Ar}^{+}$ , $\mathrm{Ar}^{++}$dan $\mathrm{He}^{+}$. Perhitungan dilakukan dengan menggunakan rapat ion $\mathrm{Ar}^{+}, \mathrm{nAr} 1=0,5.10^{16} / \mathrm{m}^{2}$, dan ion $\mathrm{Ar}^{++}, \mathrm{nAr} 2$ $=0,25.10^{16} / \mathrm{m}^{2}$.Posisi sheath mula-mula terhadap target adalah $\mathrm{s}_{\circ}=1,05 \mathrm{~cm}$, dihitung dari Pers. (23) sampai dengan Pers. (26) untuk kedua bentuk target dengan permitivitas ruang hampa $\epsilon_{\circ}=8,85.10^{12} \mathrm{~F} / \mathrm{m}$ dan muatan ion $\mathrm{q}=1,6.10^{-19}$ $\mathrm{C}$ untuk ion bermuatan tunggal. Besarnya posisi sheath mulamula ini sama untuk kedua plasma, yaitu Ar dan $\mathrm{Ar} / \mathrm{He}$, sebab $\mathrm{s}_{\circ}$ tidak bergantung pada keadaan muatan dan spesies ion . Masing-masing plasma spesies ion ini ditentukan pada tegangan yang sama dengan lebar pulsa tegangan $\mathrm{t}_{p}=1,3 \cdot 10^{-6} \mathrm{de}-$ tik. Lebar pulsa tegangan terbagi kedalam waktu naik $\mathrm{t}_{n}=$ $2.10^{-7}$ detik, waktu datar $\mathrm{t}_{d}=8 \cdot 10^{-7}$ detik, dan waktu turun $\mathrm{t}_{t}=3 \cdot 10^{-7}$ detik.

Gambar 2 dan 3 menunjukkan ekspansi sheath dinamis relatif terhadap target untuk bentuk target silinder dan bola. Akibat penggunaan pulsa tegangan yang realistis, gambaran fisis dari ekspansi sheath menjadi ekspansi sheath secara gradual, terutama seperti yang terlihat pada Gambar 2. Penggunaan tegangan realistis tidak terlalu berpengaruh untuk target bentuk bola seperti yang terlihat pada Gambar 3. Kurva pada Gambar 3 menunjukkan ekspansi sheath hampir spontan, nampak sedikit seperti ekspansi sheath yang terjadi secara gradual. Hasil perhitungan sheath ini hampir sama seperti yang diperoleh dari hasil eksperimen dan model yang dikembangkan oleh GA Emmert dan MA Henry [9] .

Gambar 4 menunjukkan rapat arus ion plasma Ar dengan bentuk konfigurasi target silinder [a] dan bola [b]. Terlihat bahwa penurunan arus terjadi sangat tajam pada bentuk target

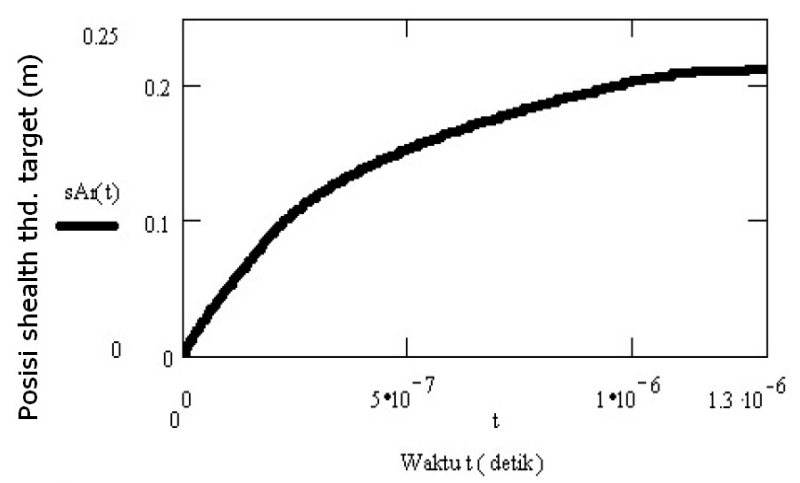

Gambar 3: Posisi sheath thd target bentuk bola untuk plasma Argon, dengan tegangan $\mathrm{V}=-20 \mathrm{kVolt}$ dan $\mathrm{n}_{I}=5.10^{14} \mathrm{~m}^{-3}$.

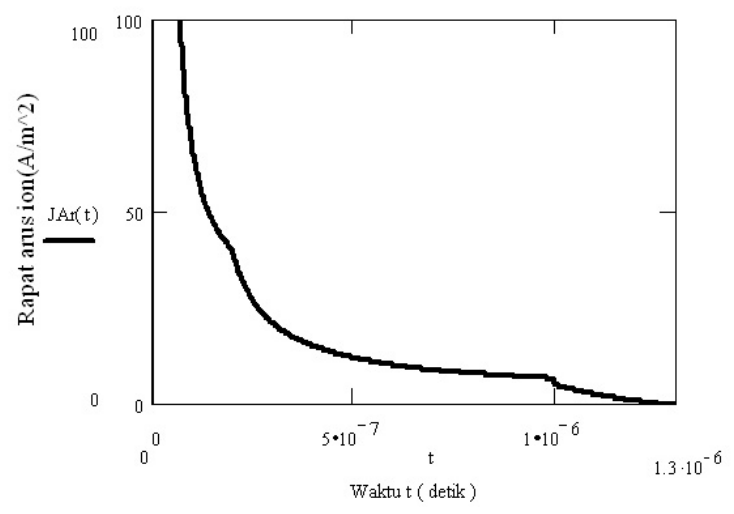

(a) silinder

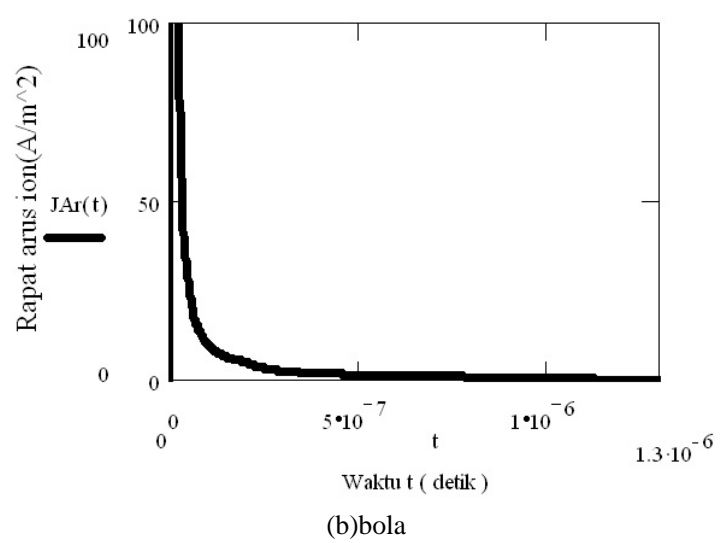

Gambar 4: Rapat Arus ion target bentuk silinder dan bola untuk plasma Argon

bola dan terjadi secara spontan, sedangkan pada bentuk target silinder ada penurunan gradual.

Gambar 5 menunjukkan ekspansi sheath dinamis plasma $\mathrm{Ar} / \mathrm{He}$ dengan komposisi ion $40 \% \mathrm{Ar}^{+}, 40 \% \mathrm{Ar}^{++}$dan $20 \%$ $\mathrm{He}^{+}$dibandingkan dengan plasma Ar dan plasma He dengan bentuk target silinder [a] dan bola [b]. Makin kecil massa efektif maka diperoleh kecepatan ekspansi yang lebih besar. Jadi karena massa $\mathrm{He}, \mathrm{mHe}=6,68 \cdot 10^{-27} \mathrm{~kg}$ paling kecil, maka ion $\mathrm{He}^{+}$mempunyai kecepatan ekspansi sheath terbesar 


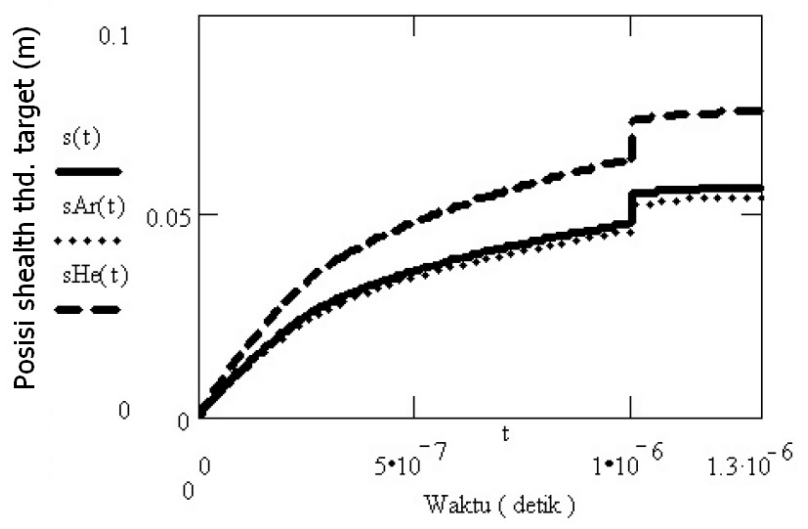

(a)silinder

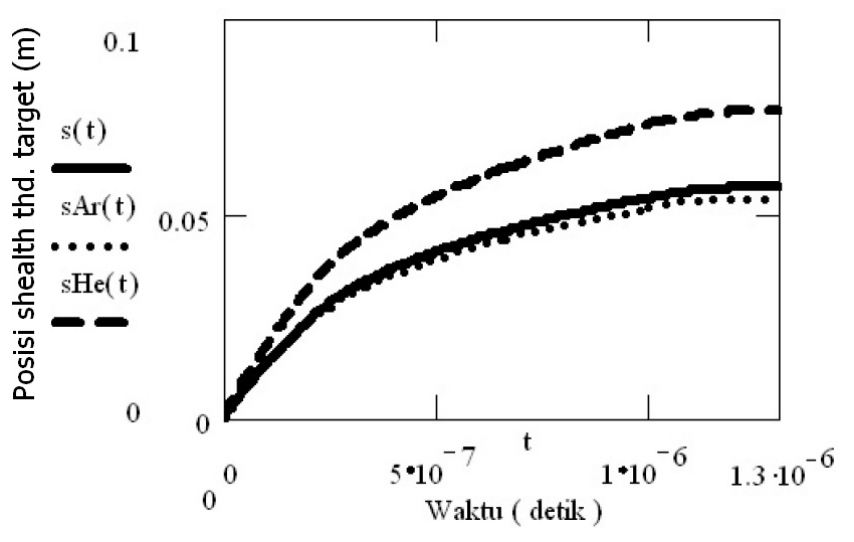

(b)bola

Gambar 5: Posisi sheath thd target bentuk silinder dan bola untuk plasma Argon/Helium (Ar/He) [2], He [1] dan Ar [3]

[kurva 1]. Sebaliknya karena memiliki massa efektif terbesar, plasma Ar memiliki ekspansi sheath terkecil, [kurva 3].

\section{SIMPULAN}

Telah dilakukan studi proses PIII dengan menggunakan model sheath dinamis tanpa tumbukan plasma multispesies bermuatan tunggal dan ganda dengan bentuk target silinder dan bola. Bentuk Pulsa tegangan yang digunakan adalah tegangan realistis. Dalam model ini ditentukan ekspansi sheath dinamis dan rapat arus ion implan total dengan menggunakan massa efektif yang merupakan fungsi dari komposisi, keadaan muatan dan massa ion dari masing-masing spesies yang berbeda. Perhitungan ekspansi sheath untuk plasma Ar pada kedua bentuk target dari model yang dikembangkan didapatkan hasil yang hampir sama dengan hasil eksperimen dan model yang telah dikembangkan oleh GA Emmert dan MA. Henry.
[1] J. R. Conrad, J. Appl. Phys. 62, 777 (1987).

[2] M. A. Lieberman, J. Appl. Phys. 66, 2926 (1989).

[3] J. T. Scheuer, M. Shamim and J. R. Conrad, J. Appl. Phys. 67, 1241 (1990).

[4] M. Shamim, J. T. Scheuer and J. R. Conrad, J. Appl. Phys. 69, 2904 (1991).

[5] S. Qin, Z. Jin and C. Chan, J. Appl. Phys. 78, 55 (1995).

[6] Yoyok Cahyono, Laporan Penelitian, Dana LitMud 1998/1999

[7] S. Qin and C. Chan, J. Appl. Phys. 79, 3432 (1996).
[8] R.A. Stewart and M.A. Lieberman, J. Appl. Phys. 70, 3481 (1991).

[9] GA. Emmert and MA. Henry, J. Appl. Phys. 71, 113 (1992).

[10] Yoyok Cahyono, Laporan Penelitian, Dana SPP/DPP 1997/1998.

[11] Joaquim Jos Barroso, Jse Osvaldo Rossi, and Mrio Ueda, IEEE Transactions On Plasma Science, Vol. 31, No. 1, Pebruari 2003 